DOI: https://doi.org/10.24867/12GI08Miletic

\title{
RAZVOJ POSLOVNOG MODELA I APLIKACIJE ZA LEČENJE FOBIJA PUTEM VIRTUELNE REALNOSTI
}

\section{DEVELOPMENT OF A BUSINESS MODEL AND APPLICATION FOR THE TREATMENT OF PHOBIAS THROUGH VIRTUAL REALITY}

\author{
Jovana Miletić, Fakultet tehničkih nauka, Novi Sad
}

\begin{abstract}
Oblast - INŽENJERSTVO INOVACIJA
Kratak sadržaj - U eri tehnološkog razvoja u kojoj se nalazimo, uviđamo mnoge velike pomake na polju medicine. Psihoterapija je dobila novi oblik i biva unapređena tehnološkim dostignućem - virtuelnom realnosti. Kroz ovaj rad je obrađen razvoj usluge i kreiranje aplikacije, koja bi pospešila tretmane lečenja fobija putem VR-a, ubacivanjem personalizovanih avatara. Takođe, razrađen je $i$ biznis plan, putem Canvas alata za izradu biznis modela, a dati su i predlozi za razvoj i sveobuhvatni zaključak.
\end{abstract}

Ključne reči : Fobije, virtuelna realnost, razvoj aplikacije, razvoj proizvoda i usluge

Abstract -In the era of technological development, we are seeing many great advances in the field of medicine. Psychotherapy has taken on a new form and is being enhanced by a technological achievement - virtual reality. This paper deals with the development of the service and the creation of an application, which would speed up the treatment of phobias via VR, by inserting personalized avatars. Also, a business plan was developed, through the Canvas tool for creating a business model, and suggestions for development and a comprehensive conclusion were given.

Ključne reči : Fobije, virtuelna realnost, razvoj aplikacije, razvoj proizvoda i usluge

\section{UVOD}

Gotovo čitav vek unazad, čovečanstvo je prvi put čulo za pojam virtuelne realnosti. Danas, ova tehnologija biva sveprisutna. Kada je dvadesetih godina prošlog veka kreiran prvi simulator veka, od strane američkog inovatora Edwina Alterta Linka [1], niko nije mogao da pretpostavi da će se sličan tehnološki princio koristiti u medicini ili nekoj drugoj oblasti primene.

Inovativni princip kakav ima VR je ubrzo pronašao svoje entuzijaste, pa je tako iz godine u godinu, sve do danas rasla mogućnost i potencijal upotrebe.

Prema definiciji iz Merriam Webster Dictionary [2], suočavamo se sa: „Veštačkim okruženjem, koje doživljavamo kroz čulne stimuluse kao što su prizori i zvukovi, kroz računar koji pokušava reprodukovati oko što se realno dešava u okruženju."

Svoju primenu je virtuelna realnost pronašla i jasno utvrdila u različitim nišama:

\section{NAPOMENA:}

Ovaj rad proistekao je iz master rada čiji mentor je bio dr Zoran Anišić, red.prof.
$>$ Turizam

$>$ Vojska

$>$ Arhitektura

$>$ Edukacija

$>$ Zabava

$>$ Sport

$>$ Filmska industrija

$>$ Medicina i zdravstvo

Kroz ovaj rad biće objašnjena primena VR-a u medicini, tačnije u psihoterapiji i još bliže kroz lečenje fobija. Fobije predstavljaju izraženi iracionalni strah, koji je najčešće prekomeran i nije opravdan, a javlja se u vezi specifičnog mesta, objekta ili situacije [3].

Prema podacima FEAROF.net, u SAD približno 8,7\% ljudi starosti 18 i više imaju najmanje jedan extremno specifični strah i približno 25 miliona Amerikanaca ima fobiju od letenja. Neke od najučestalijih fobija su [4]:

$>$ Klaustrofobija, fobija od zatvorenog prostora, a ima je preko 4\% svetskog stanovništva.

$>$ Agorafobija ili fobija od javnog mesta

$>$ Akrofobija, fobija od visine

$>$ Zoofobija ili fobija od životinja

> Arahnofobija koja se vezuje za strah od paukova

Pored ovih, nazovimo, uobičajenih fobija javljaju se i neke koje mnogima deluju bizarno ili neuobičajeno, pa tako postoji fobija od Engleske, od kikiriki putera, školjki, broja tri ili pak ćelavih ljudi. Fobije je moguće lečiti a psihoterapeuti pribegavaju različitim metodologijama. Najčešće se fobija leči razgovorom, pronalaženjem uzroka nastanka fobije a na kraju i samim suočavanjem pacijenta sa istim [5].

Jedan on načina i alternativa koje se koriste u tradicionalnim terapijama jeste podrška tehnologije odnosno virtuelne realnosti. Ova terapija se pokazala kao efektivnija od one koja koristi tehniku zamišljanja objekta ili stvari koje se čovek boji, a posebno pri lečenju specifičnih fobija [6].

Neka istraživanja pokazuju da je terapija izlaganja najučinkovitija [7]. Virtuelna realnost se već koristi u tretmanima lečenja fobija.

Aplikacije koje je moguće trenutno naći na tržištu (pre svega u Americi), bave se pored lečenja fobija i drugim elementom koji je pronašao svoj put do korisnika, a tiče se zabave.

Prikaz na Slici 1. govori o upotrebi virtuelne realnosti koju je moguće naći danas. 


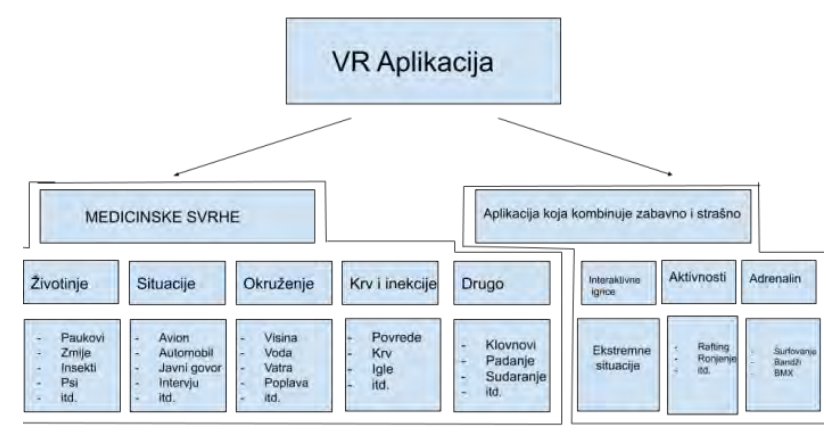

Slika 1. Prikaz strukture VR aplikacije

\section{UPOTREBA VIRTUELNE REALNOSTI U TRETMANIMA LEČENJA FOBIJA JAVNOG GOVORA}

Za potrebe ovog rada, napravljeno je istraživanje i pregled konkurencije. Uzete su dve kompanije, koje svojom uslugom pružaju mogućnost vežbanja javnog govora a i oslobađanjem od straha:

\subsection{Virual orator}

Aplikacija [8] nastala je u Americi i služi kao trening za ljude kojima je potrebno da usavrše svoje govorničke sposobnosti ili one kojima je potrebna pomoć da savladaju strahove.

Kroz ovu aplikaciju moguće je:

$>$ Videti realističnu publiku. Doživljaj prezentacije je realan. Tehnologija koja se koristi transformiše avatare $u$ virtuelne ljude ne bi li simulirali realne situacije. Klijent je u mogućnosti da bira tip publike, od zainteresovanih do manje zainteresovanih, itd.

$>$ Učestalo vežbati.

$>$ Birati situaciju. Klijentu se pruža mogućnost odabira prilike odnosno situacije na kojoj će vežbati svoj govor.

$>$ Snimati govor.

$\mathrm{Na}$ Slici 2. vidi se primer učionice sa manjim brojem slušalaca. Ovo bi po pravilu gradacije bila prva situacija sa kojom bi osoba sa strahom od javnog govora trebala da se susretne.

Mali broj ljudi, mali prostor. Pored ovakvog prikaza, moguće je naći se i u većoj učionici, amfiteatru, sali za sastanke (Slika 3), na razgovoru za posao (Slika 4.) ili držeći prezentaciju pred velikim auditorijumom. (Slika 5.)

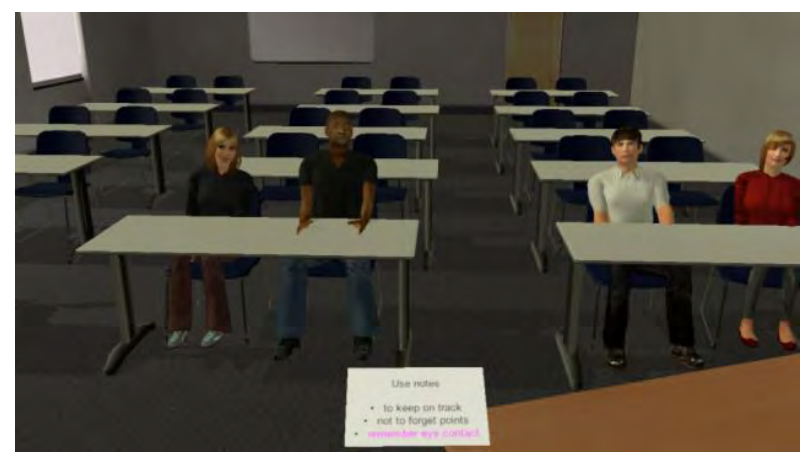

Slika 2. Primer prikaza učionice [8]

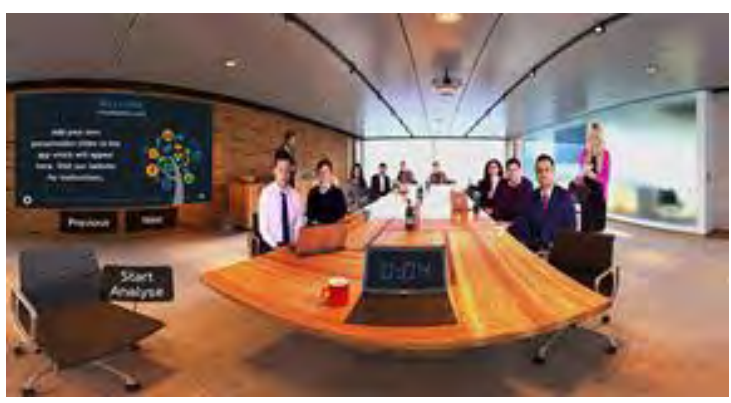

Slika 3. Primer sale za sastanke [8]

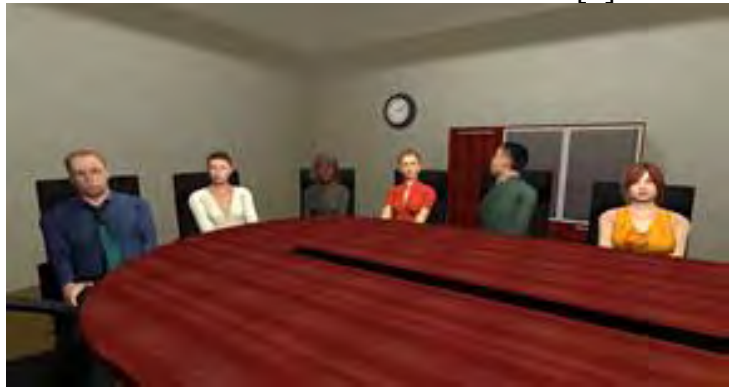

Slika 4. Primer razgovora za posao [8]

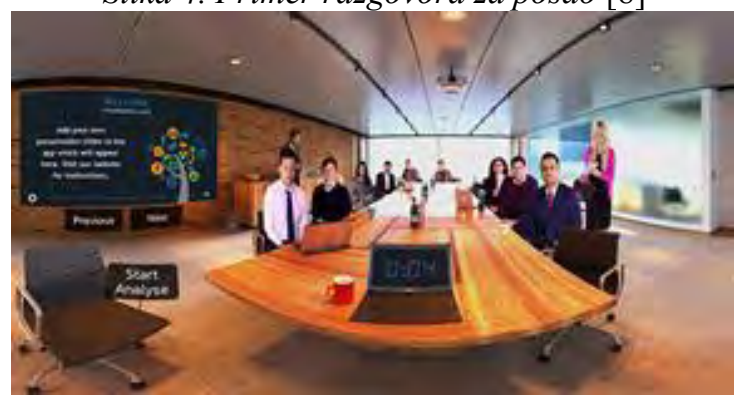

Slika 5. Primer prezentovanja [8]

\subsection{Virtualspeech VR App}

2.3. Aplikacija [9] konkurenta iz Britanije je edukativnog tipa i bavi se unapređivanjem govorničkih veština. Neke od osnovnih funkcionalnosti ove aplikacije su na prvi pogled slične Virtual oratoru, ali ono što ova aplikacija dodatno nudi jeste analitika nakon same završene sesije. Ova sjajna funkcionalnost veoma doprinosi u sagledavanju uspešnosti i toga da li se osoba zaista može istrenirati i savladati probleme koje ima a tiču se javnog govora.

Analitične izveštaje je moguće dobiti kroz direktan prikaz na samom vidnom polju kroz naočare, ali i od strane publike (virtuelne). Na ovaj način osoba može da vidi:

$>\quad$ Koliko je učestalo gledala u oči publiku

$>$ Koliko je bilo reči po minuti

$>\quad$ Da li je bilo nerazgovetnih reči (Slika 6.)

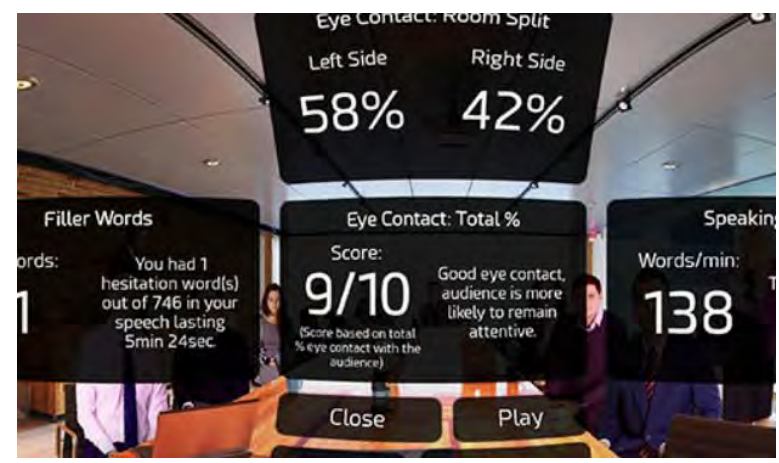

Slika 6. Prikaz analitičkog izveštaja [9] 


\section{PREDLOG PROJEKTNE IDEJE ZA UVOĐENJE PERSONALIZOVANIH AVATARA U TRETMANE LEČENJA FOBIJA PUTEM VR-A?}

Čega se čovek zapravo plaši? Kroz razgovor sa psihijatrom dr Milanom Latasom, dolazimo do zaključka da u čoveku stvaraju nelagodu sledeće situacije:
$>$ Nepoznati ljudi
$>$ Nedostatak samopouzdanja
> Nepoznati ljudi i njihovo kritičko mišljenje
$>$ Održavanje pažnje slušalaca
$>$ Buka i meškoljenje u publici
$>$ Nepoznata tema ili materija kojom govornik ne vlada

\subsection{Personalizovani avatari}

Svi ovi, ali i mnogi drugi faktori utiču na anksioznost govornika i mogu se okarakterisati kao prepreke pred koje je govornik stavljen. $\mathrm{Na}$ osnovu njih, dolazimo do zaključka kako bi na najpogodniji mogući način rešili ove probleme. Najpre, postavljamo takvu situaciju da se govornik u temi o kojoj diskutuje oseća slobodno i sigurno, a to je davanje prilike da priča o stvarima koje su mu sasvim jasne i poznate. Na ovaj način, govornik se oslobađa pritiska i mnogo lakše dolazi do izražaja njegovo poznavanje materije, a samim tim ulogu odigra i njegovo samopouzdanje.

Ključni element u ovakvoj situaciji jeste govor pred poznatim licima. Ukoliko su ispred govornika njegovi prijatelji, poznanici ili rodbina, kolege, on će na mnogo lakši način prevazići barijeru koju ima. Usresrediće se na poznato, njemu verovatno drago lice, koje će tokom svog govora fokusirati i na taj način zanemariti ljude u okolini i sve što ga je do sada sprečavalo.

Ono što doprinosi govornikovom samopozdanju, pored osobe u publici koju poznaje jeste facijalna ekspresija publike. Ukoliko su lica posmatrača blagonaklona, bez mrštenja i upitnih gestikulacija, bez zvukova koji ometaju (ispadanje olovke, zvono telefona, šuškanje i šaputanje, itd.), na mnogo lakši način će fokus i pažnja govornika biti na nivou.

Dakle u razvoju ove usluge, neophodno je sa pacijentom raditi na kreiranju njemu poznatih lica, takozvanih avatara, koji bi bili uvedeni u platformu virtuelne realnosti. Avatari bi dobijali upravo mikro facijalne ekspresije, a ceo princip ovakvih tretmana zasnivao bi se na laganom uključivanju i različitim stepenima i fazama koje bi bilo potrebno proći.

\subsection{Kako se dobijaju personalizovani avatari?}

Avatari predstavljaju grafičku prezentaciju osobe u 2D ili 3D prikazu, gde je 3D prikaz zapravo osobina avatara da se kreće u virtuelnom prostoru [10].

Prvi korak u proizvodnji 3D avatara započinje sa 3D modelovanjem. Ovaj deo predstavlja kreiranje statičkog 3D avatara [11]. Za ovu operaciju se koriste neki od sledećih alata: iClone, Maya, MakeHuman, zBrush, itd. Ove platforme koriste tehnike kako bi prikupile informacije iz kojih će kasnije 3D model biti kreiran.

Za početak je neophodno skrenirati osobu, a to se izvodi kroz različite skenere i tipove skeniranja. Informacije odnosno podaci koji se dobiju kroz skeniranje se dalje obrađuju i učestvuju u građenju 3D modela, personalizovanog. Bilo da se avatari dobijaju automatski nakon skeniranja ili poluautomatski, svakako je bitno napomenuti da je ovaj pristup značajno brži i povoljniji od kreiranja avatara od strane ilustratora, animatora ili umetnika u ovoj oblasti.

Nakon ovog, inicijalnog koraka u proizvodnji avatara, tu su i naredni koraci a to su fotogrametrija 12, dodavanje pokreta avataru 13 i korišćenje inverzne kinematike 14.

Nakon što je avatar kreiran, on se uvozi u aplikaciju i spreman je za korišćenje. Njegova kinematika odnosno pokretnost je veoma slična ljudskoj, jer se kroz prethodno pomenute korake u čovekovu grafičku strukturu integrisao ljudski skelet, sa kostima i pokretima tih kostiju i zglobova. Avatar je spreman da se kreće, skače, trči. Tu je uključeno i pomeranje vilice odnosno pokreti lica koji su karakteristični.

\subsection{Struktura aplikacije}

Kroz morfološku matricu, prikazanu na slici br. 7 . prikazana je struktura aplikacije koja bi bila kreirana. Korisniku bi bila pružena mogućnost da bira događaj kom će prisustvovati. To može biti predavanje, intervju za posao ili prezentovanje biznis ideje. Prostor u kom će se nešto od prethodno pomenutog događaja dešavati je takođe moguće birati, a to mogu biti amfiteatar, sala za sastanke, učionica ili kancelarija. Korisnik bi mogao da bira i strukturu publike, koju mogu predstavljati ljudi mlađi od 25 godina, ljudi srednjih godina ili pak ljudi stariji od 50 godina. Bira se tema o kojoj će se pričati, pa je tako moguće pričati o poznatoj, nepoznatoj ili delimično poznajtoj temi. Tu su i spoljašnji uticaji u koje spadaju reakcije iz publike, koje mogu biti od pozitivne do negativne. Tu je i ključni faktor koji predstavlja suštinu ove projektne ideje a to je struktura auditorijuma. Ovde klijent može da bira između nepoznatih lica ili uvođenjem personalizovanih avatara, njemu poznatih lica. Takođe, faktor uticaja imaju i uslovi u vidu osvetljenja i kapaciteta sale ili prostora na kom se ovakav događaj dešava.

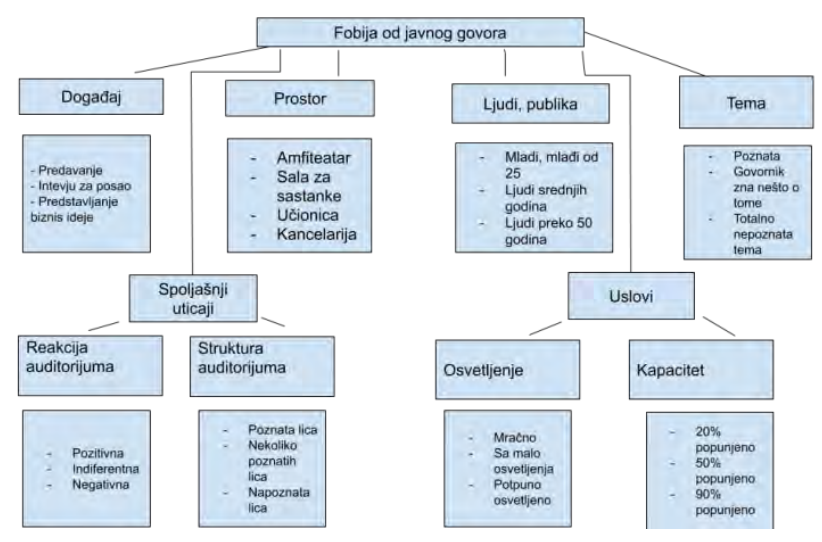

Slika 7. Prikaz morfološke matrice

\section{RAZVOJ POSLOVNOG MODELA APLIKACIJE ZA LEČENJE FOBIJA OD JAVNOG GOVORA PUTEM VIRTUELNE REALNOST}

Za potrebe pisanja ovog rada korišćen je alat za razvoj biznis modela Canvas. Biznis plan je provučen kroz svih devet tačaka ovog biznis modela i donet je zaključak da je ideja o stvaranju ovakve aplikacije finansijski isplativa. 
Uslovi za finansijsku isplativost jeste početni kapital od $50.000 €$. Za potrebe izrade same platforme i aplikacije bilo bi neophodno izdvojiti između $18.000 €$ i $20.000 €$ a u taj projekat bi bilo uključeno tri stručnjaka, dva programera i jedan dizajner.

Pored toga, bilo bi neophodno opskrbiti se sa opremom, te je ukupan iznos koja bi predstavljao inicijalni trošak bio $30.000 €$ a mesečni troškovi koji predstavljaju fiksne troškove u proseku bi iznosili 3.000€.

Sa pretpostavkom da bi marketingom uspeli da dođemo do prvih korisnika odmah nakon po kreiranju same aplikacije, a da je za kreiranje aplikacije potrebno 2 meseca, smatramo da bi u trećem mesecu već moglo ostvariti prvi profit.

Cena koštanja jednog paketa tretmana iznosila bi 250 evra, gde paket tretmana podrazumeva pet sesija.

Takođe, pretpostavka je da će se kroz mesece poslovanja broj korisnika povećavati, ali i da će korisnici koji su već koristili uslugu nastaviti iz meseca u mesec.

Ukoliko bi postojao takav trend rasta korisnika, bilo bi moguće očekivati profit već na kraju prve godine.

Napomena da za potrebe ovog rada nije rađeno istraživanje tržišta, već su informacije proistekle kao proizvod istraživanja tržišnih tokova i literature.

\section{ZAKLJUČAK}

Analiziranjem tematike kojom sam se u ovom radu bavila može se zaključiti da je pored tradicionalih metoda psihoterapije $u$ svetu dosta zastupljeno uvođenje tehnologije. Pored toga, u svrhu treniranja poslovnih veština zaposlenih primetno je uključivanje sve većeg broja tehnoloških pomagala. Ovaj trend je zastupljen više u zapadnim zemljama, što je i opravdano kupovnom moći i potrošačkom korpom.

Kreiranje personalizovanih avatara iziskuje vreme i novac, a rad psihoterapeuta na kreiranju posebnog programa za svakog klijenta takođe iziskuje dosta istraživanja, rada, ispitivanja i kreiranja. U svakom smislu te reči ovakav pristup pacijentu je krajnje personalizovan i vodi računa o mnogo segmenata jednog korisnika, ali je $u$ isto vreme moguća i njegova masovna eksploatacija, ukoliko je projekat skeniranja svakog pojedinačnog korisnika krajnje kvalitetno osmišljen i izdetaljisan.

Ovde isplivavaju organizatorske sposobnosti i kreiranje šablona za svakog klijenta, kako bi se uprostio postupak duplog rada i ponavljanja. Personalizovani avatari bi doprineli mnogo u savladavanju straha od javnog govora, jer je na osnovu mnogih istraživanja, navedenih u tekstu, upravo suočavanje sa strahom najbolje rešenje za njegovo prevazilaženje. Kombinacijom personalizovanih i generičkih avatara klijenti bi imali mnogo više prostora $i$ mogućnosti da se oslone na njima poznata lica.

Takođe, kao zaključak bitno je napomenuti da je biznis model koji je rađen isplativ, te da je sama projektna ideja potpuna. Pored toga, sama projektna ideja ima dosta mogućnosti za proširenje, u vidu licenciranja te izdavanja same aplikacije drugim psihoterapeutima.

\section{LITERATURA}

[1] VR Society: Who Coined the Term Virtual Reality?. [Online]. Available:https://www.vrs.org.uk/virtualreality/who-coined-the-term.html(Accessed on $23^{\text {rd }}$ October 2020.)

[2] Virtual Reality, Definition of virtual reality by Merriam Webster Dictionary [Online]. Available:

https://www.merriamwebster.com/dictionary/virtual\%20reality(Accessed on $23^{\text {rd }}$ October 2020.)

[3] Andrew M. Colman (2008). A Dictionary of Psychology. London, UK. Publisher: Oxford University Press, 2008. DOI: 10.1093/acref/9780199534067.001.0001

[4] Stevenson, Deborah. Review of What Are You Afraid Of?: Stories about Phobias. Bulletin of the Center for Children's Books, vol. 60 no. 2, 2006, p. 68-68. Project MUSE, doi:10.1353/bcc.2006.0699.

[5] María Elena Medina-Mora, Geoffrey Reed, "Special Issue: Mental Health”, Volume 50, Issue 8, Pages 477-586 (November 2019)

[6] Amir, Nader \& Beard, Courtney \& Taylor, Charles \& Klumpp, Heide \& Elias, Jason \& Burns, Michelle \& Chen, Xi. (2009). Attention Training in Individuals With Generalized Social Phobia: A Randomized Controlled Trial. Journal of consulting and clinical psychology. 77. 961-73. 10.1037/a0016685.

[7] A. Garcia-Palacios, C. Botella, H. Hoffman, and S. Fabregat, Comparing Acceptance and Refusal Rates of Virtual Reality Exposure vs. In Vivo Exposure by Patients with Specific Phobias, Published in Volume: 10 Issue 5: October 10, 2007

[8] Rothbaum, Barbara \& Schwartz, Ann. (2002). Exposure Therapy for Posttraumatic Stress Disorder. American journal of psychotherapy. 56. 59-75. 10.1176/appi.psychotherapy.2002.56.1.59.

[9] Virtual Orator [Online]. Available:https://virtualorator.com/(Accessed on $23^{\text {rd }}$ October 2020.)

[10] VirtualSpeech VR App [Online]. Available: https://virtualspeech.com/app-guide(Accessed on $23^{\text {rd }}$ October 2020.)

[11] James J. (Jong Hyuk) Park · Yi Pan Cheon-Shik Kim · Yun Yang, Future Information Technology, Springer Heidelberg New York Dordrecht London 2014. DOI 10.1007/978-3-642-55038-6

[12] Dragan D., Anišić Z., Mihić S., Puhalac V.: 3D Avatar Platforms: Tomorrow's Gateways for Digitized Persons into Virtual Worlds, 9. World Mass Customization \& Personalization Conference (MCPC), Aachen: Springer, 20-21 Novembar, 2017, pp. 141-156

\section{Kratka biografija}

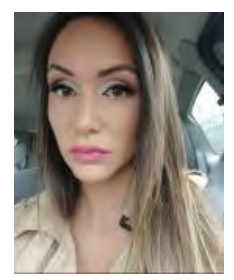

Jovana Miletić diplomirala je na Fakultetu Tehničkih nauka u Novom Sadu 2016. godine. Autor je nekoliko radova od kojih je najznačajniji rad sa međunarodne konferencije MCP-CE 2018 sa temom "The Application of Personalized Avatars in the Treatment of Phobias Using Virtual Reality”. Master rad je odbranila 2020. godine na Fakultetu tehničkih nauka u Novom Sadu. 